\title{
Lexicografia Pedagógica: Atores e Interfaces
}

\author{
(Pedagogical Bilingual Lexicography: Actors and Interfaces)
}

\author{
Magali Sanches DuRAn \\ (UNESP - S. J. Rio Preto) \\ Claudia Maria Xatara \\ (UNESP - S. J. Rio Preto)
}

ABSTRACT: Foreign learners' dictionaries have been brought out in the last thirty years and fill a need for pedagogical works that lexicographers ignored for a long time. This is a promising market, as it offers several possibilities of innovations. To better understand pedagogical lexicography, we propose in this article to identify the major actors and interfaces that affect its production. Such an exposition aims to arouse interest from Brazilian researchers about pedagogical lexicography and indirectly promote national production of pedagogic dictionaries.

KEY-WORDS: pedagogical lexicography; bilingual lexicography; pedagogical bilingual dictionary.

RESUMO: Os dicionários para aprendizes de línguas estrangeiras são obras relativamente recentes no mercado editorial e atendem uma demanda por obras pedagógicas que foi ignorada pelos lexicógrafos durante muito tempo. Esse segmento do mercado lexicográfico vem se revelando promissor, com diversas possibilidades de inovações. A fim de delinear o campo de desenvolvimento da Lexicografia Pedagógica, este artigo analisa-a sob duas perspectivas: a de suas interfaces com outras áreas da Lingüística e a de seus atores, pessoas cuja atuação influencia a produção de suas obras. Esta exposição tem o objetivo de despertar o interesse de pesquisadores brasileiros pela Lexicografia Pedagógica e, indiretamente, promover a produção nacional de dicionários pedagógicos.

PalavRas-CHave: lexicografia pedagógica; lexicografia bilíngüe; dicionário bilíngüe pedagógico.

D.E.L.T.A., 23:2, 2007 (203-222) 


\section{Introdução}

Devido em grande parte ao processo de globalização, o ensino de idiomas apresentou um crescimento sem igual no último século. Isso fomentou o desenvolvimento de todo um mercado, como pode ser constatado pela proliferação de escolas, de métodos e de ferramentas para ensino/aprendizagem de línguas estrangeiras. Há cerca de 30 anos, os dicionários, que sempre foram um importante acessório para o aprendiz de idiomas, começaram a refletir a preocupação de atender adequadamente as necessidades desse usuário. A especialização da Lexicografia para essa finalidade cresceu tanto que passou a ter denominação própria: Lexicografia Pedagógica (LP) e compreende tanto dicionários bilíngües quanto dicionários monolíngües para estrangeiros.

$\mathrm{Na}$ verdade, todos aqueles a quem direta ou indiretamente interessa o aperfeiçoamento do processo de ensino/aprendizagem de línguas estrangeiras acabam tendo interesse também pelo desenvolvimento de obras lexicográficas de cunho pedagógico. Obras dessa natureza são concebidas com a preocupação de simplificar a busca; exibir as informações de forma clara, minimizando a possibilidade de incompreensão e de conclusões ambíguas; alertar para os enganos mais comuns cometidos pelos estrangeiros; fornecer informações sobre o uso do léxico. Até detalhes como tipo de fonte, cores e leiaute de exibição são testados para facilitar a leitura e a retenção das informações. Enquanto na Lexicografia tradicional muitas vezes se julga um dicionário pela quantidade de entradas, na LP quantidade não é sinônimo de qualidade. A qualidade está, antes, relacionada ao grau de satisfação que o aprendiz sente ao fazer uso do dicionário. Binon et al (2005) discutem uma série de inovações na LP que podem inspirar novos empreendimentos na área.

No entanto, até o momento, ainda não se consolidou no Brasil um espaço para discutir a LP dentro dos diversos fóruns de discussões lingüísticas, muito embora em 2005 tenha sido formado um grupo de pesquisa em LP coordenado por Philippe Humblé, da UFSC. Alguns pesquisadores desse grupo, aliás, possuem experiência em LP anterior à formação do grupo, quando desenvolveram trabalhos envolvendo a participação de membros do Groupe de Recherche em Lexicographie Pédagogique $\left(\mathrm{GRELEP}^{1}\right)$, da

1 http://www.kuleuven.be/grelep/ 
Universidade Católica de Leuven, na Bélgica. É o caso de Vilson Leffa, da Universidade de Pelotas, RS; de Jerônimo Coura Sobrinho, do CEFETMG, e do próprio Philippe Humblé.

Até onde conhecemos, os dicionários verdadeiramente pedagógicos disponíveis no Brasil são obras traduzidas ou adaptadas de empreendimentos lexicográficos estrangeiros e, por isso, nem sempre apresentam a melhor adequação para os brasileiros. Para que se desenvolva um mercado nacional de dicionários pedagógicos projetados especialmente para atender as necessidades de aprendizes brasileiros, é preciso que a LP passe a ser divulgada e discutida no país. O presente artigo contribui para esse propósito ao mapear a área da LP de duas formas: identificando as categorias de pessoas que atuam no cenário da LP, as quais chamamos de "atores", e identificando as áreas que apresentam uma zona de intersecção de interesses com a LP, as quais chamamos de "interfaces". Os tópicos aqui discutidos, portanto, têm propósito de fomentar o interesse de pesquisadores brasileiros pela LP.

\section{Os atores no cenário da Lexicografia Pedagógica}

Para entendermos melhor o contexto de produção e de uso do dicionário pedagógico, identificamos os atores que atuam no cenário da LP, refletindo sobre quais são suas racionalidades e como eles se relacionam. Acreditamos que os principais sejam: o lexicógrafo, o editor, o professor e o aprendiz. Ressaltamos, contudo, que é comum um mesmo profissional assumir esses diferentes papéis ao longo de sua vida, podendo, inclusive, fazê-lo simultaneamente, como por exemplo, o lexicógrafo que é também editor ou o professor que é também lexicógrafo.

\section{O lexicógrafo}

A atividade de lexicógrafo vem sendo profissionalizada nos últimos tempos. Cursos para formação de lexicógrafos têm se multiplicado no mundo, tanto em nível técnico quanto em nível universitário.

Se antigamente os projetos lexicográficos eram empreendidos por lexicógrafos autônomos, hoje é mais comum serem conduzidos por editoras, que montam e treinam equipes especificamente para essa função. 
A formação do lexicógrafo é de fundamental importância para a melhoria da qualidade da produção lexicográfica. Rundell (2001) discute a necessidade de se distinguir o ensino de Lexicografia com finalidade de formar lexicógrafos, do ensino de Lexicografia com outras finalidades (como por exemplo, desenvolver habilidades de consulta nos usuários ou capacitar professores a explorarem didaticamente os dicionários).

O autor diz também que a formação do lexicógrafo deve compreender teoria e prática. Por isso, o treinamento nas editoras, ainda que revele vantagens quanto à praticidade, pelo lado teórico pode ficar prejudicado.

A formação de lexicógrafos em ambiente acadêmico cria condições propícias para que as descobertas das pesquisas possam ser incorporadas mais rapidamente na produção lexicográfica.

Em geral, o lexicógrafo quer ser o mais claro possível dentro das restrições de espaço que deve respeitar. Embora a literatura proponha diferenciar o lexicógrafo, profissional que produz dicionários, do metalexicógrafo, profissional que produz pesquisa sobre dicionários (Béjoint 2000; Hartmann e James 1998), na prática é comum haver sobreposição desses perfis.

Encontramos vários relatos lamentando o fato de a produção lexicográfica bilíngüe pedagógica ainda não ter refletido os avanços metalexicografia, muito mais do que a produção monolíngüe da mesma natureza (Béjoint \& Thoiron 1996; Worsch 1999). Isso pode estar ocorrendo por vários motivos, dentre os quais a falta de um "diálogo" entre lexicógrafos e metalexicógrafos. Na maioria das vezes, observamos que as grandes inovações lexicográficas são empreendidas justamente por pessoas que reúnem os dois perfis.

\section{O editor}

O grande editor é, quase sempre, o próprio empreendedor dos projetos lexicográficos. Seu interesse é editar obras que contenham a melhor relação entre baixo custo e alta qualidade, a fim de lograr êxito na venda e na obtenção de lucros.

O editor normalmente fornece treinamento para lexicógrafos e por isso acaba ditando as diretrizes da produção lexicográfica. Ele quer con- 
quistar o cliente final do dicionário. No entanto, no caso de dicionários voltados para aprendizes, os editores adotam estratégias de marketing especiais, a fim de conquistar os professores que, como todos sabem, influenciam os aprendizes nas compras de dicionários (Fontes 1994).

Worsch (1999) atribui aos editores a responsabilidade pelo fato de os resultados das pesquisas ainda não estarem refletidos nas publicações lexicográficas bilíngües pedagógicas. Segundo ele, os editores são extremamente conservadores no que diz respeito a dicionários, já que as obras costumam ter alto custo de produção. Talvez por isso as obras monolíngües para aprendizes apresentem mais inovações que as bilíngües: possuem um público-alvo maior (qualquer estrangeiro independentemente da língua materna) e o volume de vendas esperado encoraja novos investimentos.

No entanto, como diz Béjoint (2000), é preciso ter em mente que os aprendizes não podem comprar dicionários que não estejam à venda e, quando compram um determinado dicionário, nem sempre o fazem porque gostam de suas características, mas simplesmente porque não têm outras opções disponíveis. Isso significa que os editores só conhecerão a verdadeira demanda do mercado se ousarem lançar vários tipos de dicionários. Assim, novos tipos de dicionários poderão ser muito bem aceitos, enquanto aqueles que são hoje populares poderão sofrer queda nas vendas, ao serem lançadas obras alternativas.

\section{Oprofessor}

O professor tem consciência de seu poder de influenciar a compra de dicionários, pois seus alunos o consideram uma autoridade para realizar a escolha. Muitos professores, no entanto, ainda condenam o uso de dicionários (principalmente o dos bilíngües) e, aqueles que não o fazem, procuram recomendar dicionários que estejam em sintonia com os preceitos da abordagem metodológica que adotam.

Uma pesquisa realizada por Nesi (1999) aponta as crenças e atitudes dos professores com relação ao uso do dicionário no ensino de línguas estrangeiras. Segundo a autora, a maioria deles reconhece que os alunos carecem de habilidades para fazer bom uso do dicionário, mas consideram 
essas habilidades como pré-requisitos e eximem-se da responsabilidade de ensiná-las, alegando falta de tempo em seus planejamentos de curso.

Os próprios professores, na verdade, carecem de treinamento quanto ao uso do dicionário, por isso seria muito apropriado que a matéria constasse do programa de formação de professores de línguas estrangeiras.

Poulet (1999) relata que, na Inglaterra, ensinar ou não as habilidades de uso dos dicionários não é mais uma opção dos professores, pois as diretrizes nacionais de educação tornaram esse ensino obrigatório. Apesar disso, segundo ele, alguns professores continuam sendo contra o uso do dicionário e alegam que ele desencoraja a aquisição de vocabulário porque reduz a habilidade de inferir significados no contexto.

Esse argumento já havia sido desconsiderado por Laufer (1993), quando apontou uma má inferência como causa para que um erro se fossilize. Nesi (1999), contudo, vê a questão por outro ângulo. Ela acredita que não se pode só inferir ou só consultar o dicionário: é preciso desenvolver a habilidade para decidir quando é possível inferir com alguma margem de segurança e quando a consulta ao dicionário é realmente necessária.

\section{O aprendiz}

$\mathrm{O}$ aprendiz tem sido foco da maior parte das pesquisas que visam fornecer subsídios à LP. Seu objetivo é a aprendizagem da língua estrangeira e, para isso, procura cercar-se do que considera as melhores ferramentas. Ele quer adquirir um dicionário que atenda às suas necessidades e, quando não se sente preparado para fazer a escolha, procura orientação do professor ou compra o dicionário mais popular entre os colegas mais adiantados.

Segundo Hartmann (1999), as características que mais influenciam o aprendiz na compra do dicionário são (em ordem decrescente): relevância para as necessidades, número de unidades lexicais, número de exemplos, preço e reputação da editora. Como a pesquisa foi realizada por meio de questionário, algumas características podem não ter aparecido como opção. Talvez pudéssemos incluir na investigação outros aspectos, como durabilidade (material resistente), portabilidade (peso e volume) e potencial de aproveitamento em estágios mais avançados. 
Conhecer a identidade dos aprendizes e suas necessidades dá aos lexicógrafos melhores condições para decidir o que e como produzir (Hartmann 1999). Por isso, as pesquisas empíricas que investigam o relacionamento dos aprendizes de línguas estrangeiras com os dicionários, que há duas décadas eram raras, vêm apresentando grande expansão atualmente.

\section{Interfaces com a Lexicografia Pedagógica}

Identificamos três áreas que possuem relevantes zonas de interface com a LP: a Lingüística Computacional, a Lingüística de Corpus e a Lingüística Aplicada. Analisaremos cada uma delas separadamente, exemplificando vêm produzindo contribuições no que diz respeito à forma de disponibilização de informações lexicográficas, à forma de obtenção de informações lexicográficas e sobre as necessidades dos aprendizes.

\section{A Lingüistica Computacional}

O computador revolucionou a Lexicografia. Seu papel na atividade lexicográfica foi crescendo: de uma ferramenta para elaboração de dicionários, passou a ser fornecedor de dados de conteúdo (por meio dos corpora eletrônicos); depois se tornou também mídia para apresentação de novas obras e nos próximos anos deverá simplificar ainda mais a interação com os usuários, devido ao avanço dos estudos de processamento da linguagem natural e seu conseqüente aproveitamento nos programas de inteligência artificial.

Como mídia, o computador tem mais implicações para a Lexicografia do que podemos visualizar no momento. A princípio, já podemos observar que ela permite associar ao texto qualidades como som e imagem em movimento. Nela, a questão das restrições de espaço desaparece e restrições típicas do computador, como o formato da tela, por exemplo, passam a desafiar os lexicógrafos.

A grande vantagem de associar a obra lexicográfica ao veículo computacional é que todos os dicionários especializados poderão estar virtualmente disponíveis em um mesmo local, bastando apenas que o usuário 
defina o perfil que mais lhe convém para fazer a consulta. Assim, o armazenamento, o acesso e a apresentação das informações lexicográficas passam a ser encarados como processos relativamente independentes, ao contrário do que ocorre na mídia impressa, na qual tudo o que se armazena é exibido para o usuário.

Embora os dicionários eletrônicos tenham se tornado comuns, na maioria das vezes eles ainda imitam o leiaute dos dicionários impressos. Manning et al. (2003), acreditam que pouco se tem inovado no sentido de utilizar os recursos computacionais para enriquecer o contato do usuário com o conteúdo do dicionário.

No entanto, basta procurar um pouco para encontrarmos sinais de que a inovação já está acontecendo, tanto no que diz respeito aos métodos de acesso quanto às formas de visualização das informações lexicográficas no computador. Em modernas aplicações, as informações lexicográficas têm sido integradas a sistemas de aprendizagem de línguas por computador.

Vejamos três exemplos desses sistemas: o ELDIT, da Universidade de Bolzano, Itália; o MERLIN, da Universidade de Hull, Inglaterra; e o CATSCALLA, da Universidade de Toronto, Canadá.

O ELDIT é um sistema eletrônico de aquisição de vocabulário e, segundo Gamper \& Knapp (2003), o sistema armazena uma grande quantidade de informações para cada unidade lexical e o aluno escolhe o que quer exibir. O sistema apresenta várias opções que afetam o conteúdo exibido, como por exemplo: nível de conhecimento da língua (iniciante ou avançado), modelo (monolíngüe ou bilíngüe), domínio (geral, da área médica, técnico-científico etc.), pronúncia (local ou padrão) etc. Além disso, o sistema monitora a navegação do aluno e "aprende" o estilo dele, podendo personalizar a exibição automaticamente.

O CATASCALLA, por sua vez, é um sistema de aprendizagem de língua estrangeira por computador que propõe a utilização de textos como insumo para o processo de aprendizagem (Cummins 2003). A vantagem do sistema é que qualquer texto eletrônico de interesse do aluno pode ser aproveitado, o que aumenta a probabilidade de motivação. O sistema torna o texto compreensível por meio do uso de dicionário e de estratégias de aprendizagem, integrados num projeto de CD-ROM multimídia. 
O pressuposto básico da abordagem adotada pelo CATSCALLA é o de que quanto mais se lê na língua-alvo, mais se aprende. A consulta ao dicionário é feita por meio de hipertexto e, segundo Cummins (2003), é tão rápida que praticamente não prejudica o fluxo da leitura. $\mathrm{O}$ aluno pode escolher a ajuda de que necessita (definição na língua estrangeira, equivalente na língua materna, pronúncia, informação gramatical etc.). Terminada a leitura, o aluno tem a opção de verificar a retenção das palavras que consultou, pois estas ficam gravadas. Há também um módulo adicional com exercícios para aumentar a retenção e praticar o uso das palavras consultadas.

Já o MERLIN é um sistema que começou a ser projetado em 1995 com o objetivo de desenvolver uma plataforma na internet para fornecer cursos de línguas para aprendizes do mundo todo.

Segundo Chambers et al. (1999), o projeto MERLIN evidenciou, em sua fase de teste, que a internet é uma poderosa ferramenta para a aprendizagem de línguas, com resultados superiores aos apresentados pelo emprego da mídia tradicional. No entanto, os autores enfatizam que, para explorarmos plenamente os recursos dessa nova mídia, temos que desenvolver novos tipos de abordagem de ensino-aprendizagem.

O sistema MERLIN envolve vários módulos, inclusive com área para comunicação do aluno com o tutor e área de comunicação coletiva, tanto por escrito quanto por meio de voz. Todas as informações lexicográficas estão embutidas no sistema, mas são apresentadas em momentos diferentes, com formatos diferentes e por meio de acessos diferentes dos que conhecemos tradicionalmente na mídia impressa.

O que vemos, pois, é um novo ambiente de aprendizagem de línguas estrangeiras, que afeta tanto os papéis dos agentes participantes do processo quanto às ferramentas nele utilizadas tradicionalmente.

Dentro desse contexto, o dicionário talvez venha a perder sua identidade, mas as informações lexicográficas continuarão sendo tão ou mais preciosas para a aprendizagem de línguas quanto o são na atualidade.

Acreditamos que, se quisermos localizar onde está o dicionário pedagógico do futuro, devemos procurar pela sigla CALL (Computer Assisted Language Learning), que significa "aprendizagem de línguas mediada por computador". 
$\mathrm{O}$ interesse pelos CALL vem crescendo nos últimos anos. Evidência disso é, por exemplo, a criação da Eurocall (European Association for Computer Assisted Language Learning) em 1993.

Os CALL têm características importantes para fazer face à crescente demanda pela aprendizagem de línguas estrangeiras, como por exemplo:

- leva em conta o estilo de aprendizagem do aluno, pois apresenta opções de configuração para tornar-se mais adequado ao perfil do usuário;

- facilita o contato internacional entre professores e alunos;

- possibilita o ensino à distância, em nível nacional e internacional;

- permite a aprendizagem autônoma e auto-regulável;

- permite ao aluno ter contato com material autêntico e representativo da comunidade da língua estrangeira.

No entanto, o advento dos CALL representa uma grande mudança de paradigma e, para que tenha pleno êxito, é preciso disseminar seus conceitos a fim de preparar a comunidade para uma nova realidade.

$\mathrm{Na}$ Europa, vários cursos de pós-graduação em ensino-aprendizagem de línguas por computador vêm surgindo nos últimos anos. ${ }^{2}$ Além de tecnólogos, especialistas no ensino de línguas e outros profissionais, muitos lexicógrafos também estão envolvidos nesses projetos. Podemos citar dois jornais na internet dedicados a esse domínio: o Language Learning and Technology Journal ${ }^{3}$ e o Apprentissage des Langues et Systèmes d'Information et de Communication ${ }^{4}$.

Diante desse cenário, poderíamos chegar à conclusão de que o dicionário impresso está com seus dias contados. No entanto, segundo Levine (2001), com o advento da internet, eles não sofreram o mesmo impacto negativo sofrido pelas enciclopédias. Esse fato se explica pelo conseqüente aumento da demanda pela aprendizagem de línguas estrangeiras (em es-

2 lista atualizada pode ser obtida em: www://ourworld.compuserve.com/homepages/GrahamDavies1/courses.htm.

www://http://polyglot.cal.msu.edu/llt

www://http://alsic.univ-fcomte.fr 
pecial do inglês que, segundo o autor, é a língua de $80 \%$ das páginas virtuais). Segundo o autor, nos EUA a venda de dicionários impressos vem se mantendo estável, graças à exploração do segmento dos aprendizes, o que significa, em suma, que a internet acabou criando novos mercados para os esses dicionários.

\section{A Lingüistica de Corpus}

Dispor de um corpus e de ferramentas para explorá-lo também revolucionou a Lexicografia. Os corpora facilitaram muito a atividade dos lexicógrafos. É importante observarmos, no entanto, que nem sempre a utilização de um corpus garante qualidade ao dicionário.

A competência do lexicógrafo continua sendo extremamente importante para decidir o que deve ser selecionado para compor sua obra. Rundell (1999) aborda o assunto, dizendo que:

Deveria ser óbvio, embora nem sempre o seja, que o acesso a bons recursos de corpus simplesmente fornece a base necessária para melhores dicionários: mas não garante, por si só, que melhores dicionários serão escritos ${ }^{5}$ (Rundell 1999: 88).

O autor dá uma relação do que um corpus pode fornecer para os lexicógrafos:

- freqüência da unidade lexical que poderá apoiar decisões sobre sua inclusão ou não na nomenclatura, profundidade de seu tratamento (detalhado ou superficial), ordem de apresentação de sentidos etc.;

- informações semânticas, que permitem grande avanço no processo de desambigüização;

- comportamento combinatório da unidade lexical, permitindo identificar todas as formas de seu comportamento sintático, as colocações, o contexto típico e as restrições de seleção;

\footnotetext{
5 It should be obvious, though this point is not always recognized, that access to good corpus resources merely provides the necessary basis for better dictionaries: it does not in itself guarantee that better dictionaries will be written.
} 
- fonte de exemplos, os quais devem ser selecionados cuidadosamente, pois o fato de uma ocorrência estar no corpus não significa que é um bom exemplo;

- dados sobre a linguagem espontânea do dia-a-dia, disponíveis nos corpora de língua falada e que normalmente ainda não encontramos nos dicionários;

- características de registro (região, classe social, tipo de contexto, intenção etc.).

Essas informações podem até não ser tão relevantes para projetos de dicionários voltados a falantes nativos, mas certamente são essenciais para a LP bilíngüe ou monolíngüe voltada a aprendizes estrangeiros.

Berber Sardinha (2000) diz que a Lingüística de Corpus está revelando aspectos da língua até então ocultos. A tradicional dicotomia léxico versus gramática, segundo ele, mostra-se cada vez mais ultrapassada. Segundo o autor, os corpora vêm permitindo a identificação de padrões léxico-gramaticais, os quais são extremamente valiosos para o ensino de línguas estrangeiras, mas que permanecem praticamente ignorados pela consciência dos falantes nativos.

As revelações que a Lingüística de Corpus fez sobre unidades lexicais maiores são de grande interesse da Lexicografia, mas no vocabulário técnico lexicográfico internacional ainda não existe consenso sobre a terminologia que deve ser utilizada para referenciar tais unidades. Biderman (2001), por exemplo, relata que unidades lexicais como "guarda-roupa", "antes de ontem", "de sorte que", "tirar o pai da forca", embora constituam uma unidade de significação, ainda são classificadas indevidamente na língua, ou como lexias compostas (hifenizadas), ou como lexias complexas (sem hífen), quando deveriam ser categorizadas como lexias simples. Essa inadequação ocorre, segundo a autora, por influência da grafia.

Contudo, acreditamos que a contribuição da Lingüística de Corpus para a Lexicografia não se restringe ao levantamento de conteúdo para dicionários. Os corpora de aprendizes representam uma fonte de dados para pesquisas que visem conhecer o perfil e a necessidade do público-alvo dos dicionários pedagógicos (v. Granger 2004). Conforme salienta Berber Sardinha (2000), enquanto os estudos cognitivos nos revelam aspectos intrín- 
secos do processo de aprendizado, os estudos baseados em corpora abordam esse processo por meio de sua manifestação concreta: a produção escrita e/ ou oral dos aprendizes. Esses estudos podem ser realizados comparando o corpus de aprendizes estrangeiros com um corpus de falantes nativos e revelar sobre-uso e sub-uso de determinadas palavras ou construções. A comparação de corpora de aprendizes de diferentes nacionalidades em uma mesma língua estrangeira também é uma prática corrente, revelando semelhanças e dessemelhanças entre as interlínguas desses aprendizes, permitindo que se levantem, dentre outras, hipóteses acerca da influência das respectivas línguas maternas na produção dos aprendizes.

\section{A Lingüistica Aplicada}

A Lingüística Aplicada tem um interesse comum com a LP: descobrir meios de tornar a aquisição do léxico mais efetiva. Lingüistas aplicados abordam questão do uso dos dicionários em suas pesquisas sobre o ensinoaprendizado de vocabulário (cf. Nation 1990 e 1994; Schmitt \& Mccarthy 2000). Nation, aliás, relaciona uma extensa bibliografia sobre esse assunto em sua página pessoal ${ }^{6}$. Pesquisas sobre a aquisição, retenção e recuperação do léxico são particularmente valiosas para a LP, pois podem subsidiar decisões sobre a melhor forma de exibir as informações nos dicionários (v. Laufer \& Hill 2000).

A AILA (Associação Internacional de Lingüística Aplicada) tem uma comissão científica especialmente dedicada aos estudos em Lexicologia e Lexicografia e financiou em conjunto com a EURALEX (European Association for Lexicography), no período de 1984 a 1990, um projeto para investigar o uso dos dicionários pelos aprendizes de línguas estrangeiras. Os trabalhos produzidos dentro do projeto estão reunidos em livro (v. Atkins 1998).

O uso dos dicionários em atividades de sala de aula vem sendo disseminado, em especial pela abordagem lexical de Michael Lewis (1997). Isso estimula o mercado a produzir mais dicionários pedagógicos e cria uma importante fonte de críticas e sugestões para aperfeiçoamento dessas obras.

6 http://www.vuw.ac.nz/lals/staff/paul-nation/vocrefs/index.aspx 
Além de contribuir com seus resultados para a LP, a Lingüística Aplicada também contribui com suas metodologias de pesquisa. Técnicas de pesquisa introspectiva, por exemplo, são utilizadas para investigar o uso do dicionário pelo aprendiz de língua estrangeira, pois pouco se sabe ainda sobre quando e por que os aprendizes decidem consultar um dicionário; como o consultam; o que lêem e em que ordem lêem as informações de um verbete; quais estratégias utilizam quando não obtêm a informação desejada etc. Nessa linha, trabalhos como os de Atkins \& Varantola (1997), Christianson (1997) e Höfling (2006), que utilizam protocolos verbais e o de Harvey and Yuill (1997), que utiliza a auto-observação, mostram que existe uma diversidade de perfis de comportamento de usuários e apontam duas oportunidades de melhorar o uso dos dicionários: o aperfeiçoamento dessas obras e a instrução sobre como utilizá-las.

\section{Os atores no cenário da Lexicografia Pedagógica}

Para entendermos melhor o contexto de produção e de uso do dicionário bilíngüe pedagógico, identificamos os atores que atuam no cenário da LP, refletindo sobre quais são suas racionalidades e como eles se relacionam. Acreditamos que os principais sejam: o lexicógrafo, o editor, o professor e o aprendiz. Ressaltamos, contudo, que é comum um mesmo profissional assumir esses diferentes papéis ao longo de sua vida, podendo, inclusive, fazê-lo simultaneamente, como por exemplo, o lexicógrafo que é também editor ou o professor que é também lexicógrafo.

\section{O lexicógrafo}

A atividade de lexicógrafo vem sendo profissionalizada nos últimos tempos. Cursos para formação de lexicógrafos têm se multiplicado, tanto em nível técnico quanto em nível universitário.

Se antigamente os projetos lexicográficos eram empreendidos por lexicógrafos autônomos, hoje é mais comum serem conduzidos por editoras, que montam e treinam equipes especificamente para essa função.

A formação do lexicógrafo é de fundamental importância para a melhoria da qualidade da produção lexicográfica. Rundell (2001) discute a 
necessidade de se distinguir o ensino de Lexicografia com finalidade de formar lexicógrafos, do ensino de Lexicografia com outras finalidades (como por exemplo, desenvolver habilidades de consulta nos usuários ou capacitar professores a explorarem didaticamente os dicionários).

O autor diz também que a formação do lexicógrafo deve compreender teoria e prática. Por isso, o treinamento nas editoras, ainda que revele vantagens quanto à praticidade, pelo lado teórico pode ficar prejudicado.

A formação de lexicógrafos em ambiente acadêmico cria condições propícias para que as descobertas das pesquisas possam ser incorporadas mais rapidamente na produção lexicográfica.

Em geral, o lexicógrafo quer ser o mais claro possível dentro das restrições de espaço que deve respeitar. Embora a literatura proponha diferenciar o lexicógrafo, que produz dicionários, do metalexicógrafo, que produz pesquisa sobre dicionários (Béjoint 2000; Hartmann e James 1998), na prática é comum haver sobreposição desses perfis.

Encontramos vários relatos lamentando o fato de a produção lexicográfica bilíngüe pedagógica ainda não ter refletido os avanços da pesquisa metalexicográfica (Béjoint \& Thoiron 1996; Worsch 1999). Isso pode estar ocorrendo por vários motivos, dentre os quais a falta de um "diálogo" entre lexicógrafos e metalexicógrafos. $\mathrm{Na}$ maioria das vezes, observamos que as grandes inovações lexicográficas são empreendidas justamente por pessoas que reúnem os dois perfis.

\section{O editor}

O grande editor é, quase sempre, o próprio empreendedor dos projetos lexicográficos. Seu interesse é editar obras que contenham a melhor relação entre baixo custo e alta qualidade, a fim de lograr êxito na venda e na obtenção de lucros.

O editor normalmente fornece treinamento para lexicógrafos e por isso acaba ditando as diretrizes da produção lexicográfica. Ele quer conquistar o cliente final do dicionário. No entanto, no caso de dicionários voltados para aprendizes, os editores adotam estratégias de marketing especiais, a fim de conquistar os professores que, como todos sabem, influenciam os aprendizes nas compras de dicionários (Fontes 1994). 
Worsch (1999) atribui aos editores a responsabilidade pelo fato de os resultados das pesquisas ainda não estarem refletidos nas publicações lexicográficas bilíngües pedagógicas. Segundo ele, os editores são extremamente conservadores no que diz respeito a dicionários, já que as obras costumam ter alto custo de produção.

No entanto, como diz Béjoint (2000), é preciso ter em mente que os aprendizes não podem comprar dicionários que não estejam à venda e, quando compram um determinado dicionário, nem sempre o fazem porque gostam de suas características, mas simplesmente porque não têm outras opções disponíveis. Isso significa que os editores só conhecerão a verdadeira demanda do mercado se ousarem lançar vários tipos de dicionários. Assim, novos tipos de dicionários poderão ser muito bem aceitos, enquanto aqueles que são hoje populares poderão sofrer queda nas vendas, ao serem lançadas obras alternativas.

\section{Oprofessor}

O professor tem consciência de seu poder de influenciar a compra de dicionários, pois seus alunos o consideram uma autoridade para realizar a escolha. Muitos professores, no entanto, ainda condenam o uso de dicionários (principalmente o dos bilíngües) e, aqueles que não o fazem, procuram recomendar dicionários que estejam em sintonia com os preceitos da abordagem metodológica que adotam.

Uma pesquisa realizada por Nesi (1999) aponta as crenças e atitudes dos professores com relação ao uso do dicionário no ensino de línguas estrangeiras. Segundo a autora, a maioria deles reconhece que os alunos carecem de habilidades para fazer bom uso do dicionário, mas consideram essas habilidades como pré-requisitos e eximem-se da responsabilidade de ensiná-las, alegando falta de tempo em seus planejamentos de curso.

Os próprios professores, na verdade, carecem de treinamento quanto ao uso do dicionário, por isso seria muito apropriado que a matéria constasse do programa de formação de professores de línguas estrangeiras.

Poulet (1999) relata que, na Inglaterra, ensinar ou não as habilidades de uso dos dicionários não é mais uma opção dos professores, pois as diretrizes nacionais de educação tornaram esse ensino obrigatório. Apesar dis- 
so, segundo ele, alguns professores continuam sendo contra o uso do dicionário e alegam que ele desencoraja a aquisição de vocabulário porque reduz a habilidade de inferir significados no contexto.

Esse argumento já havia sido desconsiderado por (1993), quando apontou uma má inferência como causa para que um erro se fossilize. Nesi (1999), contudo, vê a questão por outro ângulo. Ela acredita que não se pode só inferir ou só consultar o dicionário: é preciso desenvolver a habilidade para decidir quando é possível inferir com alguma margem de segurança e quando a consulta ao dicionário é realmente necessária.

\section{O aprendiz}

$\mathrm{O}$ aprendiz tem sido foco da maior parte das pesquisas que visam fornecer subsídios à LP. Seu objetivo é a aprendizagem da língua estrangeira e, para isso, procura cercar-se do que considera as melhores ferramentas. Ele quer adquirir um dicionário que atenda às suas necessidades e, quando não se sente preparado para fazer a escolha, procura orientação do professor ou compra o dicionário mais popular entre os colegas mais adiantados.

Segundo Hartmann (1999), as características que mais influenciam o aprendiz na compra do dicionário são, por ordem de importância: relevância para as necessidades, número de unidades lexicais, número de exemplos, preço e reputação da editora. Como a pesquisa foi realizada por meio de questionário, algumas características podem não ter aparecido como opção. Talvez pudéssemos incluir na investigação outros aspectos, como durabilidade (material resistente), portabilidade (peso e volume) e potencial de aproveitamento em estágios mais avançados.

Conhecer a identidade dos aprendizes e suas necessidades dá aos lexicógrafos melhores condições para decidir o que e como produzir (Hartmann 1999). Por isso, as pesquisas empíricas que investigam o relacionamento dos aprendizes de línguas estrangeiras com os dicionários, que há duas décadas eram raras, vêm apresentando grande expansão atualmente. 


\section{Considerações finais}

O desenvolvimento da LP abre o ambiente da produção lexicográfica para a participação de setores da sociedade que tradicionalmente ficavam à margem desse processo. Tudo indica que esse segmento da Lexicografia vai ganhar status de uma nova disciplina, principalmente por demandar uma série de pesquisas não tradicionais na Lexicografia, pesquisas que focam não a matéria lexicográfica em si, mas a obtenção de subsídios que auxiliem a elaborar obras cada vez mais adequadas ao ensino/aprendizagem do léxico.

Recebido em outubro de 2005

Aprovado em dezembro de 2006 E-mails:magali.duran@uol.com.br xatara@lem.ibilce.unesp.br

\section{REFERÊNCIAS BIBLIOGRÁFICAS}

Atkins, B. S. (ed.) 1998. Using Dictionaries: Studies of Dictionary Use by Language Learners and Translators. Tübingen: Niemeyer.

Atkins, B. S.; Varantola, K. 1997. Monitoring Dictionary Use. International Journal of Lexicography, v. 10, n. 1. Oxford: OUP.

BÉJOInt, H. 2000. Modern Lexicography: an Introduction. Oxford: Oxford University Press.

BÉJOINT, H.; ThOIRON, P. 1996. Les dictionnaires bilingues. Louvain-la-Neuve: Duculot: 5-15.

Berber Sardinha, T. 2000. Computador, corpus e concordância no ensino da léxico-gramática de língua estrangeira. In: Leffa, V. J. (org.) As palavras e sua companbia - o léxico na aprendizagem. Pelotas: EDUCAT: 71-94.

Biderman, M. T. C. 2001. Teoria lingüística. São Paulo: Martins Fontes. Binon, J., S. Verlinde, Th. Selva, A. Bertels en J. Van Dyck. 2005. Quelques innovations récentes dans le domaine de la lexicographie pédagogique. La contribution du Dictionnaire d'Apprentissage du Français des Affaires (DAFA) (version papier et électronique). Disponível em http://www.kuleuven.be/grelep/publicat/publicin.htm. Acesso em 07 fev. 2006. 
Chambers et al. 1999. Thematic Network Project in the area of Languages, Subproject 3: New Technologies and Language Learning, Final Report for Year Three. Disponível em: www.fu-berlin.de/elc/tnp1/SP3dossier.doc tnp 1. Acesso em: 27 nov. 2003.

Cummins, J. Computer Assisted text Scaffolding for Curriculum Access and Language Learning/Aquisition. Disponível em: http://www.iteachilearn.com/ cummins. Acesso em: 03 out. 2003.

Fontes, W. M. 1994. Marketing Password in Brazil. Kernerman Dictionary News. Tel-Aviv, n.1, jul. 1994. Disponível em: <http// www.kdictionaries.com >.Acesso em: 15 ago. 2002.

Gamper, J.; Knapp, J. Adaptation in a Language Learning System. Disponível em: < http://www.kbs.uni-hannover.de/ henze/ABIS_Workshop 2001/final/Gamperfinal>. Acesso em: 23 ago. 2003.

Granger, S. Computer learner corpus research: current status and future prospect. 2004. In: Connor U. and T. A. Upton (eds.) Applied Corpus Linguistics: A multidimensional Perspective. Amsterdam \& Atlanta: Rodopi: 123-145.

Hartmann, R. R. K. 1999. Case study: the Exeter University survey of dictionary use. In: Hartmann, R. R. K. (ed.) Thematic Network Projects, Sub-project 9 - Dictionaries - Dictionaries in Language Learning, Final Report Year Three, p. 36-52. Disponível em: < http://www.fu-berlin.de/ elc/tnp1/SP9dossier.doc tnp 1> Acesso em: 04 jul. 2003.

Hartmann, R. R. K.; James, G. 1998. Dictionary of Lexicography. Londres: Routledge.

Harvey, K.; Yuill, D. 1997. A Study of the Use of a Monolingual Pedagogical Dictionary by Learners of English Engaged in Writing. Applied Linguistics, v.18, n. 3. Oxford: OUP.

HöFling, C. 2006. Traçando um perfil de usuários de dicionários - estudantes de Letras com Habilitação em Língua Inglesa: um novo olhar sobre dicionários para aprendizes e a formação de um usuário autônomo. Tese (Doutorado em Lingüística e Língua Portuguesa) - Faculdade de Ciências e Letras de Araraquara, Universidade Estadual Paulista, Araraquara.

Laufer, B.; Hill, M. 2000. What Lexical Information Do L2 Learners Select in a Call Dictionary and How Does It Affect Word Retention? Language Learning E Technology, v. 3, n. 2: 58-76.

Laufer, B. 1993. The effect of dictionary definitions and examples on the use and comprehension of new L2 words. Cabiers de Lexicologie, n. 63: 131-142. Paris. 
LewIs, M. 1997. Implementing the Lexical Approach: Putting Theory into Practice. Hove: Language Teaching Publications.

Nation, P. 2001. Learning vocabulary in another language. Cambridge: Cambridge University Press. . 1990. Teaching and Learning Vocabulary. Boston: Heinle \& Heinle.

NeSI, H. 1999. The specification of dictionary reference skills in higher eduction. In: Hartmann, R. R. K. (ed) Thematic Network Projects, Subproject 9 - Dictionaries - Dictionaries in Language Learning, Final Report Year Three. p. 53-67. Disponível em: <http://www.fu-berlin.de/elc/ tnp1/SP9dossier.doc tnp 1>. Acesso em: 04 jul. 2003.

Poulet, G. 1999. Instruction in dictionary use and foreign language teacher training: the English scene. In: Hartmann, R. R. K. (ed.) Thematic Network Projects, Sub-project 9 -Dictionaries - Dictionaries in Language Learning, Final Report Year Three, p. 78-82. Disponível em: < http:// www.fu-berlin.de/elc/tnp1/SP9dossier.doc tnp 1>. Acesso em: 04 jul. 2003.

Rundell, M. 1999. Recent trends in publishing monolingual learners' dictionaries. In: Hartmann, R. R. K. (ed.) Thematic Network Projects, Sub-project 9 - Dictionaries - Dictionaries in Language Learning, Final Report Year Three, p. 83-98. Disponível em: < http://www.fu-berlin.de/ elc/tnp1/SP9dossier.doc tnp 1> Acesso em: 04 jul. 2003. . 2001. Teaching Lexicography or Training Lexicographers? Kernerman Dictionary News, Tel-Aviv, n. 9, jul. Disponível em: <http/ /www.kdictionaries.com >.Acesso em: 15 ago. 2002.

Schmitt, N.; McCarthy, M. 1997. Vocabulary: Description, Acquisition and Pedagogy. Cambridge: CUP.

Worsch, W. 1999. Recent trends in publishing bilingual learners' dictionaries. In: Hartmann, R. R. K. (ed): Thematic Network Projects, Sub-project 9 - Dictionaries - Dictionaries in Language Learning, Final Report Year Three, p. 99-107. Disponível em: www.fu-berlin.de/elc/tnp1/ SP9dossier.doc tnp 1. Acesso em: 04 jul. 2003. 